\title{
Rationality and the unit of action
}

\author{
Christopher Woodard
}

Abstract: This paper examines the idea of an extended unit of action, which is the idea that the reasons for or against an individual action can depend on the qualities of a larger pattern of action of which it is a part. One concept of joint action is that the unit of action can be extended in this sense. But the idea of an extended unit of action is surprisingly minimal in its commitments. The paper argues for this conclusion by examining uses of the idea of an extended unit of action in four theoretical contexts. It also explains why the idea of an extended unit of action need not involve magical thinking, and discusses possible replies to an objection based on a worry about recklessness.

Keywords: Action; reasons; Team Thinking; joint action; plans

One concept of joint action is of an action composed of parts such that the reasons to perform each part depend on the qualities of the whole. For example, electing the government might be considered a joint action in this sense, because it might be thought that each government-supporting voter's reason for casting her vote depends on the effects of the election as a whole. The crucial idea here is that the focus of our attention should be on the part-whole relationship — not any cause-effect relationship-between the individual vote and the election. On this way of thinking of each voter's action, the reason to perform it is not that it causes the election of the government, but that it is part of the election of the government. I will explain further below what difference this makes.

This concept of joint action-which I shall refer to as the idea of an extended unit of action - is a component of some much richer concepts of joint action. But in itself it is a surprisingly minimal idea, or so I shall argue in this paper. Few conditions must be satisfied for individual actions to be related in such a way that the reasons for each may depend on the qualities of the whole pattern of action of which they are parts. The agents concerned needn't share any goals, or be willing or intending to cooperate with each other, for example.

Like other concepts of joint action, the idea of an extended unit of action can feature in claims about normative reasons for action as well as in claims about the reasons that explain why an agent acted as she did. These uses are not wholly independent of each other. Arguably, the explanatory claims are in good order only if the idea of normative reasons based on an extended unit of action makes sense. ${ }^{1}$ In this

\footnotetext{
${ }^{1}$ Sugden (2000: 191) disagrees. I do not mean to deny that agents sometimes act for reasons that are not genuine normative reasons. The suggestion instead is that a form of explanation of action-for example, in
} 
respect, perhaps, the normative applications of the idea are more basic. In any case, my focus in this paper will be on the idea that an agent could have normative reasons for action associated with an extended unit of action.

My method will be to survey several different contexts in which the idea of an extended unit of action has been deployed within philosophy and allied disciplines. Discussions within each context tend to operate largely in isolation from each other. Pointing out the common elements at work in each may help us to keep an open mind about what is involved in the idea of an extended unit of action, since what appears to be an obvious requirement in one context may not appear so obvious in another context. The result of keeping this open mind, I will claim, is the conclusion that we should not build much into the concept. None of this, of course, is meant to deny that there are other concepts of joint action which are much richer and have more demanding conditions.

Section 1 clarifies the idea of an extended unit of action, by contrasting it with more standard ways of thinking about reasons for action. Section 2 surveys some uses of the idea of an extended unit of action in four distinct theoretical contexts. Section 3 defends the minimal version of the idea as I have outlined it from two objections: first, the objection that it involves magical thinking; and second, the objection that it involves a kind of recklessness. Section 4 concludes. Throughout, I'll use the phrase 'the actor' to refer to the individual agent whose normative reasons for action are under discussion.

\section{The idea of an extended unit of action}

The phrase 'unit of action' is a term of art. I will use it as follows:

Unit of action The extent of action whose qualities (goodness, rightness) provide reasons for or against performing some action $A .^{2}$

The purpose of defining this concept is to draw attention to a common but contestable assumption about reasons for action, which is that the unit of action is always identical to the actor's options. If we make this assumption, we think that reasons for or against an option $A$ are always provided by the goodness of rightness of $A$ itself (in comparison with the goodness or rightness of her other options, perhaps). This assumption might be correct. However, we should consider the possibility that it is not, and that, as I will put

terms of the idea of an extended unit of action-makes sense only if the normative ideas used in the explanation are intelligible. Admittedly, the threshold of intelligibility may be rather low. For empirical evidence that people use 'team reasoning', see Colman et. al. (2008).

${ }^{2}$ In Woodard (2008b: 63) I defined the idea with respect to 'the deliberative stance'. For present purposes, the definition I have given in the text is more appropriate (though the two definitions, properly understood, express the same idea). 
it, the unit of action extends beyond the actor's options. For short, I will call this the idea of an extended unit of action.

This idea implies that there can be a reason for or against some action, $A$, because it is part of some larger pattern of action, $P$, which is good or right. As I shall sometimes say, it is the idea that there are pattern-based reasons (Woodard 2008b). Such reasons exist, if at all, because $A$ is a part of $P$, regardless of whether it is a cause of $P$ (Hurley 1989: 148). That is, the idea is not that there is a reason to perform $A$ because it will bring about $P$, or make $P$ more likely. Instead it is that the goodness or rightness of $P$ provides reasons to perform its parts, just in virtue of their being parts of it. There may of course be constraints on which patterns of action can support such reasons-eligibility constraints, as I'll call them. Some of these may have to do with the prospects of the larger pattern being realised. But the crucial point for now is that the idea of pattern-based reasons is not the commonplace idea that there can be a reason to do something because it will lead to some sequence of actions that is good or right. As we'll see shortly, evaluating reasons in terms of an extended unit of action in fact involves suspending our usual predictive stance towards parts of the actor's environment. This is a puzzling feature of the idea, which I shall try to explain.

How, in principle, could it turn out that the unit of action extends beyond the actor's options in some cases? One idea is that this could be so only if the actor could participate in some larger exercise of agency. For example, suppose that genuinely joint actions are possible. ${ }^{3}$ One might then think that the actor could have a reason associated with the goodness or rightness of any joint actions in which she could participate. If she could participate in electing the government, for example, and we think that this would be a genuine exercise of joint agency, then we might think that she could have a reason for or against casting her individual vote that depends on the qualities of the joint action. That would be an instance of an extended unit of action due to the prospect of an exercise of extended agency.

According to what I'll call the mirroring assumption, this is the only way in which the unit of action could be extended. This assumption claims that the unit of action always matches, and is determined by, the unit of agency. ${ }^{4}$ This implies that there could be a reason to perform $A$ because it is part of pattern $P$ only if there is a prospect of an

\footnotetext{
${ }^{3}$ An action is 'genuinely joint' only if it is, or would be, performed by a genuinely extended agent. This claim is deliberately schematic, doing no more than connecting the two concepts of joint action and extended agency; in particular, it does not tell us what is required for either genuine joint action or for genuinely extended agency. I use these terms as placeholders to help characterize the idea of the mirroring assumption. This assumption is general: it can be combined with many different (and rival) views about the necessary and sufficient conditions for the existence of extended agency or of joint action.

${ }^{4}$ I learned the concept of what I call the 'unit of action' from Susan Hurley. She tended to use the phrase 'unit of agency' instead to describe this concept (1989: 145-148). This usage has been somewhat influential. However, I prefer 'unit of action' because it makes it easier to see that the mirroring assumption is a substantive thesis. In later work (e.g. 2005), Hurley used the phrase 'unit of activity'.
} 
extended agent performing $P$. So, the actor could have a pattern-based reason to play her part in some good joint action only if there is a prospect of the relevant group constituting an agent and performing that joint action. In this way the mirroring assumption embeds the idea of an extended unit of action within the idea of extended agency.

However plausible the mirroring assumption may seem, it is not a logical requirement of the idea of an extended unit of action itself. The concept of the unit of action refers to the idea of an extent of action. If we suppose that the unit of action is extended, this means that the relevant extent of action includes actions other than the actor's immediate options. But it does not follow from this idea that the actions which constitute the unit of action must be, as it were, fused together in a single exercise of agency (as the mirroring assumption claims). That is a further, substantive, controversial idea.

So there are two conditions under which the unit of action could be extended beyond the actor's immediate options. First, there might be a prospect of genuine extended agency, in which the actor's options play some part. This is consistent with the mirroring assumption. Second, however, the mirroring assumption might be false, in which case there need not be any prospect of extended agency. In $\$ 2$ we will see some examples of uses of the idea of an extended unit of action which adopt the mirroring assumption, and some which do not. One purpose of the discussion is to highlight the importance and contestability of this assumption.

Thus the bare idea of an extended unit of action (or of pattern-based reasons) is compatible with, but does not presuppose, the idea that there can be units of agency other than individuals. It does presuppose that the larger pattern, $P$, is performable in some sense. But that could be merely a matter of each of its parts being performable.

We can now characterise more precisely the standard view of reasons for action, from which the idea of pattern-based reasons is a departure. According to this view, the unit of action is always identical to the action in which we're interested. If we're interested in the reasons for or against $A$, the unit of action is $A$ itself, according to the standard view. Thus we can call the reasons that exist according to this view act-based reasons. Now, it is worth pointing out that there can be act-based reasons for participating in patterns of action. So the advocate of the standard view is not committed to the implausible claim that individuals never have normative reasons for cooperating, or for sticking to plans, for example. However, these reasons must depend on the goodness or rightness of the individual acts of participation themselves. Roughly, this means that there is a reason to participate in a good larger pattern because of its goodness only if doing so raises the probability of the realisation of that pattern. Perhaps doing so 
encourages others to participate, for example, or in some other way makes it more likely that the pattern will be realised.

To see what is distinctive about the idea of pattern-based reasons for participation, let us consider a specific example. Suppose we're interested in Art's reasons for action. His problem is whether to go to the café or the park for lunch. He'd prefer meeting Susie to not doing so, and meeting her in the park to meeting her in the café. She has the same preferences, mutatis mutandis. Unfortunately, neither can remember the arrangement they made, and they have no way of communicating. All these facts are common knowledge amongst them.

According to the standard view, Art's reasons depend on the goodness or rightness of each of his options, namely café and park. Let's assume that neither of these options is intrinsically right or wrong; so we're interested only in their goodness. The goodness of each of them depends on Susie's choice. If she chooses café, Art does best to choose café too. If she chooses park, on the other hand, he does best to choose park. If he has a credible prediction of her choice he may be able to settle on one of these options.

However, the symmetry of their situation may make this difficult. His prediction is likely to depend on Susie's reasons, if she is rational. If it is based entirely on an assessment of her reasons, as in game theory, then he is locked in a circle, since his reason to choose one option rather than the other depends on her reason to do likewise, and her situation is exactly symmetrical to his (Hurley 1989: 154-155; Regan 1980: Chapter 2; Sugden 2000: 179-181). Thus game theory may suffer from a problem of indeterminacy in simple coordination problems such as this. ${ }^{5}$

Now suppose that we claim that the unit of action for Art's choice between café and park includes not just his behaviour but Susie's. (Shelve for the moment any concerns about the rationale for doing this; we're just trying to see what's involved in the idea.) This means that we consider the rightness or goodness of the various possible combinations of choices they could make. Once again we can assume that no combination is intrinsically right or wrong, so that we have only their goodness to consider. Of the possible combinations, both choosing park is, they both agree, the best. Thus (assuming Art's reasons in this case depend on his preferences) we may say that Art has a pattern-based reason to choose park, since that is his part in the best pattern of action that he and Susie could perform.

Note the following two very important points about this train of thought. The first is that there is no danger of falling into the circle that orthodox game theory can find

\footnotetext{
${ }^{5}$ Note that this is not endemic to all theories of rationality that conform to the standard view, since there could be some different basis for the prediction of the other agent's behaviour, such as salience (Schelling 1980: Ch. 3).
} 
itself trapped in, since Art's reasons are not said to depend on Susie's reasons. Art's reasons depend instead on what it would be best for them both to do (as do her reasons). This is part of the attraction of the idea of an extended unit of action. However, the second point highlights a possibly troubling feature of the idea, while explaining the first point. The reason that there is no danger of falling into the circle is that Art's reasons are not said to depend on how Susie would react to his choice. The circle arises when we say that one agent's reasons depend on how another agent would react, and our prediction of that reaction depends on assessing the second agent's reasons, in cases where those reasons are symmetrical to the first agent's reasons (Sugden 2000: 191). It's obvious that we can avoid this at the first step, by denying that the first agent's reasons depend on how the second agent would react. But many find that an absurd claim, and this explains most of the resistance to the idea of an extended unit of action.

So the idea of an extended unit of action is equivalent to the idea that there can be pattern-based reasons. Just by itself, this idea does not require that the larger pattern would be performed if the actor plays her part in it. As we have just noted, in fact, the idea shifts our attention away from the question of whether the other parts of the larger pattern would be performed (in response to the actor's part) altogether. Instead, what matters is whether the whole pattern could be performed and would be good or right. This displacement of our usual predictive stance towards the way the actor's environment would respond to her action is puzzling, and gives rise to the main objections to the idea of an extended unit of action.

I will consider these objections in $\S 3$, having first illustrated some ways in which the idea of an extended unit of action has been employed, in $\S 2$.

\section{Four contexts in which the idea is used}

2.1 One important context in which we find the idea of an extended unit of action is in debates about the foundations of game theory and decision theory. Orthodox views in these areas define rational action in terms of the consequences of the various individual actions open to the actor. ${ }^{6}$ That is, they conform to what I have called the standard view of reasons for action, and claim that reasons are always act-based. As is well known, however, these accounts of rationality face various difficulties in certain collective action problems and their intrapersonal analogues, and this has led some theorists to propose

\footnotetext{
${ }^{6}$ Of course there is an important difference between expected and actual consequences. But since this issue is orthogonal to those discussed in this paper, I will ignore it.
} 
revised accounts of rationality incorporating use of extended units of action (Bacharach 2006; Gold and Sugden 2007; McClennen 1985, 1990).

The prisoner's dilemma (PD) is probably the best-known example of a collective action problem. Consider the two-player, one-shot version of this game shown in Figure 1.

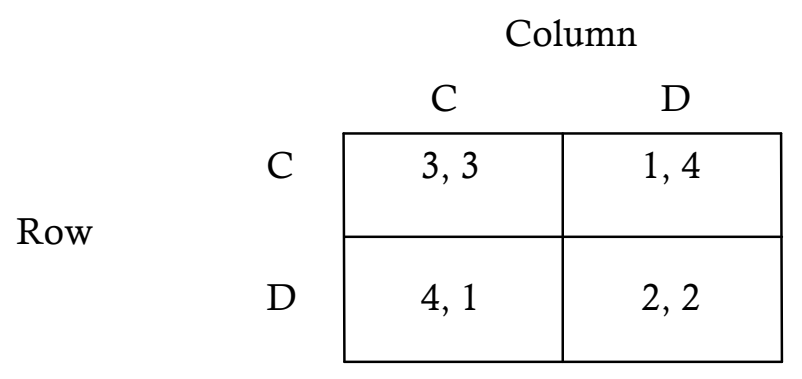

Figure 1: A two-person, one-shot PD

Row's payoffs are given by the first figure in each cell, while Column's payoffs are given by the second. A higher figure denotes a better payoff, by the lights of the player concerned. Each player faces a choice between two actions: $C$ and $D$. Each player's choice is causally independent of the other's. The result of each action depends on the choice of the other player, in the way shown by the matrix. Thus, if both players choose $D$, the result is an outcome that each values at 2. If Row chooses $D$ while Column chooses $C$, the result is an outcome that Row values at 4 , but which Column values at 1 ; and so on. ${ }^{7}$

As is familiar, there is a simple and powerful argument to the effect that the rational choice for each player is $D$. First consider things from Row's point of view. Suppose Column were to choose $C$. Then the result of Row choosing $C$ would be worse, by Row's lights, than the result of Row choosing $D$. Now suppose Column were to choose $D$. Again, the result of Row choosing $C$ would be worse, by Row's lights, than the result of Row choosing $D$. So, whatever Column chooses, Row does better to choose $D$. Choosing $D$ is Row's best reply, whatever Column chooses-which is to say that $D$ is a dominant strategy for Row. If we consider things from Column's point of view, the situation is entirely symmetrical. Once again, choosing $D$ is dominant, since it is the best reply to the other's choice, whatever that is. Plausibly, rationality requires choice of

\footnotetext{
${ }^{7}$ We need not ask why each player values these outcomes in these ways. It could be a matter of self-interest, altruism, theology, or something else. All that is necessary is that the outcomes are valued in the ways shown, and depend on the players' actions in the ways shown.
} 
dominant strategies when they are available. So, plausibly, rationality requires that each player choose $D$ in this case. ${ }^{8}$

However, the result of both players choosing $D$ is an outcome that each values less than each values the result of both choosing $C$. That is, the result of each player choosing $C$ is strongly pareto superior to the result of each player choosing $D .{ }^{9}$ Hence, doing the thing that rationality plausibly requires in this case leads the players away from an outcome that is possible and that both agree is better. This seems to be bad news: either for rationality itself, or for our understanding of what it requires (Colman 2003; Parfit 1987: 53-55).

What, if anything, has gone wrong? One diagnosis is as follows. The concepts of best-reply and dominant strategy both conform to the standard view of practical reasons, since they make claims about the actor's reasons based on an assessment of the difference some one action at a time would make, holding other actions constant. A best-reply, after all, is a choice that maximises the actor's payoff given the other player's choice. A strategy is dominant just in case it picks out a best-reply no matter what the other player chooses. Both concepts therefore examine the differences that could be made to the outcome by single actions. ${ }^{10}$ The argument for choosing $D$ thus makes use of a series of what we might call horizontal and vertical comparisons between cells in the payoff matrix. Holding Row's choices constant, it uses horizontal comparisons to examine the differences Column's choices could make. Holding Column's choices constant, it makes vertical comparisons to examine the differences Row's choices could make. It may consider several such comparisons. What it never does is make the crucial diagonal comparison between the result of both players choosing $D$ and the result of both choosing C.

The concept of pareto superiority applies to this diagonal comparison, of course-but pareto superiority is a guide to value, not to reasons for action. Orthodox game theory and decision theory use no diagonal comparisons in their claims about reasons, because doing so would involve violating the standard view of reasons, to which they are committed. If we try to derive a reason to choose $C$ in the PD from the comparison of $<\mathrm{C}, \mathrm{C}>$ with $<\mathrm{D}, \mathrm{D}>$, for example, we are saying that there is a reason to

\footnotetext{
${ }^{8}$ Howard (1988) discusses a case in which each player can detect the other's decision rule, and argues that it would be rational to choose $C$ if each player has a rule which says roughly "choose $C$ if and only if the other has this same rule'. He also shows that this need not involve any regress.

${ }^{9} X$ is weakly pareto superior to $Y$ when some prefer $X$ and none prefer $Y$. $X$ is strongly pareto superior to $Y$ when all prefer $X$ to $Y$.

${ }^{10}$ The same is true of the concept of Nash equilibrium, and David Lewis's concept of a 'coordination equilibrium' (1986: 14).
} 
choose $C$ because it is part of a larger unit of action that is favourable. ${ }^{11}$ This contradicts the standard view.

In light of this, some theorists propose revising the orthodox account of rationality in game theory and decision theory. Robert Sugden has developed an account of 'Team Thinking' which makes use of the idea of an extended unit of action. In Sugden's theory, it can be rational to engage in Team Thinking when one has teamdirected attitudes and the other members of a relevant group do too, such that every member of the group conceives of themselves as acting as part of the team and seeks to maximise a shared team utility function. When those conditions are met, the actor has a reason to play her part in the profile of actions by the members of the group that would maximise the shared utility function (Bacharach 1999, 2006; Colman et. al. 2008; Gold and Sugden 2007; Sugden 1993: 84-89, 2000: 190-203). ${ }^{12}$ If we assume that the players in a PD satisfy these conditions, and that the shared utility function ranks $\langle\mathrm{C}, \mathrm{C}\rangle$ as uniquely best, then each player has a reason to choose $C$. In this way the theory of Team Thinking combines two important ideas: an extended unit of action, such that the actor's reason to choose $C$ is derived from the goodness of the profile of actions that produces $<\mathrm{C}, \mathrm{C}\rangle$; and a team-level evaluation of the outcomes, such that $\langle\mathrm{C}, \mathrm{C}\rangle$ is ranked as best from the 'team's point of view', as we might put it. I'll return briefly to this second idea later. The resulting account of rationality helps explain intuitions about reasons for action not just in the PD but in a range of collective action problems (Gold and Sugden 2007). ${ }^{13}$

2.2 A more familiar context for moral philosophers might be debates about the structure of consequentialism. Act Consequentialism conforms to what I've called the standard view of reasons. It accounts for reasons in terms of the goodness of individual actions, and so claims that they are always act-based. In contrast, Rule Consequentialists explain reasons in terms of the goodness of widespread compliance with, or acceptance of, sets of rules. If the explanation is given in terms of compliance it is clear that this amounts to use of an extended unit of action in the sense at stake here. These forms of Rule Consequentialism aim to account for reasons for or against individual actions in

\footnotetext{
11 ' $<\mathrm{C}, \mathrm{C}>$ ' here denotes the outcome produced by both players' choice of $C$.

${ }^{12}$ Sugden writes that '[n]othing in this account of team agency purports to tell people when they oughtwhether morally or rationally - to act as members of teams' (2000: 195, emphasis in the original). One might interpret this as claiming that the theory of Team Thinking has no normative content at all. However, I think that is a mistake. The burden of Sugden's claim seems to be, instead, that it is a mistake to think that rationality (or morality) requires that individuals think in team-directed ways. But the theory of Team Thinking remains (conditionally) normative in the following sense: it tells one what it is rational to do, if one has the appropriate team-directed attitudes.

${ }^{13}$ McClennen $(1985 ; 1990)$ proposes a theory of 'resolute choice' which modifies decision theory by adopting an intrapersonally extended unit of action. This helps to explain some intuitions about rational sequential choice in cases that are intrapersonal analogues of collective action problems.
} 
terms of the goodness or badness of widespread compliance with sets of rules. But compliance with a set of rules may be understood as a very extended pattern of action, consisting of every occurrence of compliant action. Thus these forms of Rule Consequentialism employ the idea of an extended unit of action (Woodard 2008a: 260).

Other variants of consequentialism also employ the idea of an extended unit of action. Collective Consequentialism explains reasons for or against individual actions in terms of the goodness of larger patterns of action performable by some relevant group (Mulgan 2001: Chs. 3-4). Plan Consequentialism explains reasons in terms of the goodness of a larger pattern of action performable by the actor herself (Feldman 1997; McClennen 1985, 1990). Cooperative Consequentialism explains reasons in terms of the goodness of the best pattern of action performable by all cooperative agents (Hurley 1989: 136-159, 1991, 1994, 2005; Regan 1980). Other variants may also use the idea of an extended unit of action. Any so-called 'indirect' version of consequentialism that explains reasons in terms of something that amounts to a pattern of action uses this idea.

2.3 Consider now a third context. There is a debate in deontic logic between socalled 'actualists' and 'possibilists' (Bergström 1966; Goldman 1976; Jackson 1987; Jackson and Pargetter 1986; Sobel 1976; Zimmerman 1996: Ch. 6). These two camps disagree about the concept of moral obligation. Actualists claim that obligation depends on facts about how the actor's environment would respond to the choices she could make. These facts could include facts about her own response to those choices. In one of the central examples, Professor Procrastinate has been invited to review a book (Jackson and Pargetter 1986: 235). He faces a sequence of choices. Now he must either accept or reject the invitation; if he accepts now, later he will face a choice between writing or not writing the review. The best outcome would be reached by accepting now and writing later. The next best outcome would be reached by declining now. The worst outcome would be reached by accepting now, but not writing later. Though he could accept or decline, and he could write or not write, as a matter of fact he would not write later, were he to accept now. Actualists believe that this fact about his own response to accepting the invitation implies that he ought to decline. Possibilists deny this, and claim that it lets Procrastinate off the hook too easily. They claim that what he ought to do now depends on how he could best respond later, not on how he would respond later. Thus, they treat the actor's own response differently from the response of other parts of her environment. They claim that we should focus on the best response she could make, but on the response the rest of her environment would make.

The debate between actualists and possibilists is usually couched in terms which obscure its relevance to the idea of an extended unit of action. It tends to be described as 
being about which consequences of an individual action matter for obligation. Actualists claim, of course, that it is the 'actual' consequences that matter-where this means the consequences the action would have, were it performed. Possibilists claim, in contrast, that 'merely possible' consequences matter. But note that they are interested only in certain very specific merely possible consequences: namely, those that would occur were the action in question performed, and the actor were to perform some other action she could perform. Possibilists are not interested in any other merely possible consequences, such as those that would follow were the weather different than it will be, or were some other agent to behave in some way he will not. Only those possible consequences that are accessible by some combination of actions performable by the actor are said to matter.

For this reason it is more perspicuous to conceive of the debate between actualists and possibilists as being about whether an extended unit of action, which includes only actions performable by the actor, generates reasons for her to act now. Rather than being about which consequences of individual actions matter (the 'actual' versus the 'merely possible'), it is better to think of it as being about the relevant unit of action, the ('actual') consequences of which matter. Putting things this way explains which particular 'merely possible' consequences are the subject of the dispute, and thereby makes better sense of possibilist views (Jackson 1987: 106; Woodard 2009). Possibilist versions of consequentialism are thus best understood as versions of Plan Consequentialism. ${ }^{14}$

\subsection{The final context I wish to discuss is Kantian ethics. One reason to include it is to} counteract the impression that may have been gained that the idea of an extended unit of action is relevant only to theories that are, in a broad sense, consequentialist. Each of the proposals I've discussed in the other three contexts used the idea of the good consequences of a larger unit of action to make claims about reasons to perform parts of it. But there is nothing essentially consequentialist about the idea of an extended unit of action.

Indeed, this idea may be essential in Kantian ethics. One respect in which it seems important is in the idea of an imperfect duty. According to Kant some duties, such as the duty not to lie, are perfect; others, such as the duty to develop one's talents, are imperfect (Cummiskey 1996: 114-122). This contrast seems to be a matter of laxity in guiding individual actions. Perfect duties set strict limits, requiring certain things on specific occasions. For example, the perfect duty not to lie requires that, on every occasion in which it is possible for me to lie, I do not lie. In contrast, imperfect duties do

\footnotetext{
${ }^{14}$ I do not claim that understanding possibilism as a form of Plan Consequentialism resolves all problems with it. There are still difficult issues about specifying what the actor could do, for example. Instead, the claim is that understanding it in this way explains why the possible outcomes that possibilists believe are relevant only ever include ones accessible by sequences of action that the actor could perform. This feature of possibilism is otherwise mysterious.
} 
not require specific actions on specific occasions. For example, I can comply with the duty to develop my talents even while I am skipping the faculty research seminar to play a mind-numbing video game, so long as I develop my talents sufficiently on other occasions. Because it is imperfect, this duty does not imply that any particular action is forbidden or required. ${ }^{15}$ Instead, imperfect duties seem to imply that lives, or anyway extended periods of lives, with certain characteristics are forbidden or required. A life without development of one's own talents, for example, is forbidden. Though I can skip the research seminar this time, I cannot pass up similar opportunities every time they arise - for then I would have lived an impermissible life.

This picture of imperfect duties suggests that the idea of an extended unit of action is required to explain how imperfect duties ever give rise to reasons to perform individual actions. If I have a reason to go to the research seminar because of the imperfect duty to develop my own talents, for example, that reason must have the following form: going to the seminar is a constituent of one of the permitted lives, of which I am required to live one. Thus, a reason to perform individual action $A$ is said to depend on the rightness of some larger unit of action (in this case, a series of actions constituting a permitted life). Kantian ethics thus seems to make important use of the idea of an extended unit of action. ${ }^{16}$

2.5 This brief survey of proposals in four contexts suggests the following points. First, it is clear that the idea of an extended unit of action is recurrently attractive. As I've said, each of these discussions tends to occur without much reference to any of the others. This suggests the following sociological speculation: the same idea somehow occurs to people who are interested in rationality, as being part of an attractive view for some purpose, more or less independently of its having occurred to others working on related questions in different contexts. Whether or not that speculation is true, the idea of an extended unit of action is certainly recurrently attractive, and I take that to be evidence that it merits attention. We should try to understand this idea and the issues it raises.

Second, the proposals fall into various types. One obvious dividing line is between views that limit the extended unit to the actor's own behaviour, and those which allow it to extend across individuals. Possibilism, Plan Consequentialism, and Kantian imperfect duties use the idea for the actor's own behaviour only. Rule Consequentialism, Collective Consequentialism, Cooperative Consequentialism, Team Thinking, and

\footnotetext{
${ }^{15}$ There are limiting cases which complicate this story. Presumably, the duty forbids committing suicide. I shall set these complications aside.

${ }_{16}$ If Parfit (2011) is right that we can think of Kantian contractualism as converging with Rule Consequentialism, and I am right that Rule Consequentialism depends centrally on the idea of an extended unit of action, we might conceive Kant's ethics as using this same idea more generally, not just with respect to imperfect duties.
} 
(perhaps) other elements of Kantian ethics use the idea for other individuals' behaviour. Obviously, this issue is extremely important for the character of the resulting views. A second dividing line is more specific. This is between views that impose specific eligibility constraints on the behaviour that can form part of the unit of action, and those that do not. Cooperative Consequentialism, for example, disallows any behaviour that is not the behaviour of a cooperative agent. Team Thinking requires not just cooperativeness, but also that every agent conceives of herself as acting as part of the team and shares the team-level objective. Rule Consequentialism, on the other hand, extends the unit of action to include the behaviour of all those capable of performing the type of action in question, whether or not they are cooperatively disposed or identify as part of the group of all such agents. Third, some views marry the idea of an extended unit of action with the idea of group-level evaluation, while others do not. Certainly these two ideas are conceptually distinct, though it might be possible to argue that the first is implausible without the second (Woodard 2003: 215).

Some of these differences might reflect different attitudes towards what I have called the mirroring assumption. Since this assumption tends not to be articulated, this is only a speculative interpretative hypothesis. However, it could help explain, for example, why possibilists extend the unit of action only to the actor's own behaviour, or why Team Thinking requires team identification and shared team-level evaluation. In each case, the theorists might be presupposing the mirroring assumption, and tacitly assuming that the phenomena in question constitute the only examples of genuinely extended agency. Other proposals, such as Rule Consequentialism, clearly do not accept the mirroring assumption.

\section{Two objections: magical thinking and recklessness}

In $\S 1$, I noted that the idea of an extended unit of action sometimes requires that we substitute a concern with what could happen in response to the actor's actions for our usual concern with what would happen. In particular, it requires this substitution when we are considering any possible behaviour that is included in the unit of action itself. This was what enabled Art to coordinate with Susie, but it also invites a number of objections. Two of the most important are as follows. First, does this substitution rely on magical thinking, to the effect that the actor can control the others' responses? Second, isn't it reckless to substitute concern with how the others could respond for our usual concern with how they would respond?

The first objection is that extending the unit of action to include other agents' behaviour involves some sort of magical thinking (Elster 1989: 192-202). In particular, it 
might be thought to rely on the tacit assumption that the actor has the power to determine what other relevant agents will choose. For example, if we suppose that Art has a pattern-based reason to choose park because it is part of the best pattern performable by him and Susie, it might be thought that we are supposing that his choice would bring it about that the best pattern is realised. That would amount to believing that, by choosing park, he could cause Susie to do the same.

In some specific situations this sort of control of another's response might be possible. But of course it is not generally possible, which is why this sort of assumption is appropriately described as 'magical thinking'. However, the idea of an extended unit of action is in no way committed to such thinking. Art's pattern-based reason to choose park, supposing he has one, does not depend on any claim about how Susie would respond to that choice. As I explained above, it is supposed to follow from the fact that his going to the park is part of the best pattern they could perform. It thus depends on claims about what each of them could do. But it does not rely on any claims about what either of them would do. To suppose otherwise is to misunderstand the nature of the idea of an extended unit of action, or of pattern-based reasons.

Far from relying on predictions based on dubious magical thinking, pattern-based reasons don't rely on predictions (about behaviour that is part of the unit of action) at all. Though we usually adopt a predictive stance towards the behaviour of relevant parts of our environment when deliberating, we suspend this stance towards behaviour that is part of the unit of action. The standard view of practical reasons recognises this with respect to the options open to the actor, of course. No-one thinks that in deliberating whether to choose $A$ or $\sim A$, I should try to predict whether I will choose $A$ or $\sim A$. Predicting other behaviour by myself might be pertinent; but predicting the very thing under deliberation is not. This is not because the nature of human freedom makes such predictions impossible. It is just because such predictions are irrelevant to the question being asked. In deliberating about $A$ or $\sim A, \mathrm{I}$ am asking myself which of these options is best or right. Answering 'I will choose $A$ ' or 'I will choose $\sim A$ ' simply fails to address the question. For this reason, deliberation about a piece of behaviour 'crowds out' prediction of that piece of behaviour. ${ }^{17}$

The same goes for your choice of $B$ or $\sim B$, if that behaviour of yours is part of the unit of action for my choice of $A$ or $\sim A$. When I include your behaviour in the unit of action, I address myself to the goodness or rightness of the various possible combinations of $A, \sim A, B$, and $\sim B$. If that is the question I'm strictly interested in, it is irrelevant to ask whether you will choose $B$ or $\sim B$. (This is not to say that I should lose all interest in predicting your behaviour. For example, I might want to include your behaviour in the

\footnotetext{
${ }^{17}$ The phrase- though not the explanation—is Levi's (1997: ix).
} 
unit of action only if I judge you to be cooperative (Regan 1980), which is to make a kind of prediction, though not of your choices. Or, as I shall suggest below, I might want somehow to combine concern with pattern-based reasons and concern with act-based reasons in a single case. If I do that, I should retain an interest in predicting your behaviour insofar as I am deliberating about my act-based reasons.)

Pattern-based reasons do not depend on causal claims about the relationship between the part-the action for which there is said to be a reason-and the completion of the pattern. They depend on parthood relations, not causal relations, between the constituent action and the favoured pattern. ${ }^{18}$ This explains why deliberation about pattern-based reasons involves suspending our normal predictive stance towards all parts of the pattern. Because we are not asking whether the pattern would come about, but whether it would be good or right, it is irrelevant to predict that this or that part of it would or would not be performed.

This is not always fully appreciated. Once we have cleared up this confusion, however, the outlook may seem worse for the idea of pattern-based reasons. One imagines a sceptic saying, 'if that's what you mean, let's hear no more of it!'.

In particular, suspending the predictive stance can seem reckless. Claiming that there is a reason to do such and such, because this is part of a good or right pattern of action, without making the reason conditional on predictions about completion of the pattern, seems like an invitation to bring forward cases in which acting unilaterally on such reasons would have disastrous consequences. For example, suppose that the best pattern of behaviour by drivers on UK roads involves their all driving on the right hand side of the road (since that would minimise the risk of accidents when they drive elsewhere). Surely it's crazy to claim that any individual driver in the UK has a reason to drive on the right, where that reason does not depend on any prediction about whether the others will do so too?

The worry about recklessness may seem unanswerable. In fact, there are at least four distinct ways for the advocate of pattern-based reasons to respond to it. Here I will simply outline these four ways, rather than defending in detail the response I think best. My aim is to dispel the air of indisputability in a way that does not depend on the reader's attitude to my specific theoretical commitments.

One response is to claim that pattern-based reasons exist only in specific contexts, where the contexts are described in ways such that acting on these reasons does not seem reckless. The leading version of this idea restricts pattern-based reasons to cooperative contexts. For example, Regan's 'Cooperative Utilitarianism' bids each agent to '[hold]

\footnotetext{
${ }^{18}$ One complication is that an individual action's causal properties might be crucial in making it part of the favoured pattern. For example, an act of voting is part of the pattern electing the government only because it has certain causal properties. I am grateful to an anonymous referee for this point.
} 
himself ready to co-operate with whoever else is willing and able to co-operate . . . [and then to identify] the other co-operators and [do] his part in the best possible pattern of behaviour for the class of co-operators (including himself) in view of the behaviour of the non-cooperators' (Regan 1980: 136). Though this is strictly speaking a claim about a decision procedure rather than about reasons, it would be natural for someone holding this view to claim also that there are no pattern-based reasons except when others are cooperative.

Of course, one must be careful to define 'cooperative' and 'potential cooperator' in ways that do not reintroduce the predictive stance. But this seems possible. Regan, for example, defines cooperativeness in terms of decision procedures. Thus, when deliberating using Cooperative Utilitarianism we seek to recognise others' decisions procedures rather than seeking to predict their choices as such (Regan 1980: 142, 178). ${ }^{19}$ As he says, '[w] hat each member of [the group of cooperators] needs to know about each other member ... is just that each other member will eventually act on the best plan as he (the other member) sees it when he comes to the last step [of deliberation] . . . It is not necessary for one member . . . to know what other members will do under any other description than this' (Regan 1980: 142, emphasis in the original). Providing we can define 'cooperative' in some appropriate way such that we can identify cooperators without predicting their ultimate choices, claims about pattern-based reasons can be conditional on cooperativeness even though they are not conditional on predictions of specific behaviour. The former kind of conditionality may seem sufficient to avoid recklessness. $^{20}$

A second possible response to the worry about recklessness is to adopt some device designed to steer agents away from disaster. Rule Consequentialists do this when they argue that one of the rules in the best set instructs the actor to break the other rules if necessary to avoid disaster (Hooker 2000: 98-99; Woodard 2008a). In normal cases, Rule Consequentialism claims that we each have pattern-based reasons that are unconditional on any facts about others' responses. I should tell the truth even if you won't, because of the good consequences of widespread truth-telling. However, Rule Consequentialists typically recognise that there can be unusual cases in which following rules that are

\footnotetext{
${ }^{19}$ Recognition of decision procedures is a central feature of Howard's treatment of one-shot PDs, too (1988).

${ }^{20} \mathrm{~A}$ variant of this first response to the worry about recklessness claims that pattern-based reasons exist only when all the agents involved together satisfy conditions of joint agency-which presumably include, but go beyond, the sort of cooperativeness that does the work in the previous proposal (Sugden 1993: 87). This is one way of motivating the mirroring assumption described in $\S 1$, and it may explain why some claim that the unit of action can be extended only intrapersonally. However, once we've seen the possibility of restricting pattern-based reasons to cooperative contexts, it's not clear that considerations of recklessness speak in favour of further restriction to situations in which there is a prospect of joint agency. This further restriction just seems gratuitous. It's not clear, for example, that others' intentions to engage in a joint action with me further reduces the risk of my performing my part in a favoured pattern, as compared with their intentions simply to cooperate with me in producing the best pattern.
} 
usually benign would have disastrous consequences. By permitting or requiring the agent to break those rules in such cases, a disaster-prevention rule ameliorates the worry about recklessness. The upshot is a theory with a dual stance on whether the responses others would make affect the actor's reasons. In normal cases, they do not; but in cases where disaster looms, they do.

A third response to the worry about recklessness is to restrict pattern-based reasons to kinds of action that seem important enough for the apparent recklessness of performing them unilaterally not to seem a sufficient objection to doing so. This is one way of understanding deontological ethical theories such as Kant's. These theories pick out certain kinds of action that, if universally performed, would constitute a pattern of action that is good or right. They then claim, of those specific actions, that one should perform them unilaterally, no matter which consequences may follow. In saying this, they are not thereby committed to general endorsement of pattern-based reasons. Only certain patterns of action are eligible to support reasons, and not all patterns meet that test. Not lying might meet it, for example, even though driving on the right hand side of the road does not.

These three kinds of response to the worry have their advantages and disadvantages. Elsewhere I have advocated a fourth kind of response (Woodard 2003, 2008a, 2008b). If we are pluralists in the sense of permitting more than one unit of action for a single decision problem, we can claim that pattern-based reasons sometimes conflict with act-based reasons in a single case. This means that we can give an account of pattern-based reasons that is not restricted to any particular context or kind of action, while allowing that facts about how other agents would respond are vitally important, since they affect the nature and strength of possibly countervailing act-based reasons. This sort of structure has the advantage of being able to explain intuitions about conflicting reasons across a wide range of cases, and also of finding a natural home for facts about others' responses. The natural home for such facts is in claims about act-based reasons. So long as we are pluralists, we do not have to find some surrogate device for avoiding recklessness. How you would respond matters to my reasons, just not to any pattern-based reason I have in respect of a unit of action that includes your response. But since such a pattern-based reason must be considered alongside my other reasons, facts about your response may affect its relative strength. ${ }^{21}$

The worry about recklessness is not a knockdown argument against the idea of an extended unit of action. I have described four possible ways of responding to it, and there may well be others. Certainly, those who utilise the idea of an extended unit of action

\footnotetext{
${ }^{21}$ One debt this response incurs is to give some account of how act-based and pattern-based reasons may interact in a single case. For discussion see Woodard (2008b: 107-118).
} 
ought ultimately to have a convincing response to this worry. As things stand, it is reasonable to think that some such response could be developed. Given the recurrent attractiveness of the idea of an extended unit of action, and the fact that this idea does not rely on magical thinking, this strengthens the case for further debate about the relative merits of all of these possibilities.

\section{Conclusion}

One of the many uses for the idea of joint action is in our understanding of reasons for action. In particular, it has seemed appealing to many of those who have studied reasons for action to make use of what I have called the idea of an extended unit of action, or of pattern-based reasons. This is the idea of a reason to perform some action because it is part of some larger pattern of action that is good or right. It is striking that this idea recurs in many theoretical contexts in which rationality is discussed. If the idea is correct, there is a sense in which an idea of joint action-specifically, the idea of patterns of action performable by many individuals - is involved in our understanding of the reasons that individuals have. ${ }^{22}$

The idea of an extended unit of action stands opposed to the standard view of normative reasons for action, according to which these depend only on the goodness or rightness of each individual action. Pattern-based reasons are reasons for an action that depend on the goodness or rightness of some larger pattern, of which the immediate action is a part. They thus depend on parthood relations, not causal relations, between the favoured pattern and the action under consideration.

I suggested that the fact that this idea recurs in different contexts should make us interested in it. This fact is not evidence that the idea is correct, but it is evidence that it is worth understanding the idea well. It also suggests that there may be theoretical benefits in abstracting from the details of specific proposals made in one context or other, to consider the fundamental features of the idea as it appears across these different contexts. One such feature is that pattern-based reasons are not conditional on facts about whether the rest of the pattern would be realised. This explains why, when deliberating with some extended unit of action in mind, we suspend our normal predictive stance in respect of any behaviour that forms part of the unit. Doing this is not an instance of magical thinking - which would be, on the contrary, a matter of retaining the predictive stance, but making unjustified predictions on the supposition that the actor has the power to control responses to her choices.

\footnotetext{
${ }^{22}$ If the mirroring assumption is correct, then the idea of an extended unit of action depends on a richer conception of joint action, according to which the larger pattern must be performable by an extended agent. However, I pointed out in $\S 1$ that the mirroring assumption is contestable.
} 
However, clarification of this point leads to a different objection. It can seem reckless to suspend the predictive stance. In line with my general method in this paper, I surveyed four different responses to this worry that could be made by advocates of pattern-based reasons. I did not argue for any of these responses, but merely claimed that, in light of their existence, the worry about recklessness should not be treated as a knockdown objection to the idea of an extended unit of action, and nor should advocates of one specific version of this idea assume that their particular response is the only genuine candidate. Pointing out the variety of ways of constructing a theory of patternbased reasons should lead those of us interested in the idea to examine the different possibilities more closely. Doing that might also enable us to export insights gained in one context to one or more of the others. ${ }^{23}$

\section{References}

Bacharach, M. (1999). Interactive Team thinking: A Contribution to the Theory of Cooperation. Research in Economics, 53: 117-47.

Bacharach, M. (2006). Beyond Individual Choice. Teams and Frames in Game Theory. Gold, N. and Sugden, R. (eds.). Princeton: Princeton University Press.

Bergström, L. (1966). The Alternatives and Consequences of Actions. Stockholm: Almqvist and Wiskell.

Colman, A. M. (2003). Cooperation, Psychological Game Theory, and Limitations of Rationality in Social Interaction. Behavioral and Brain Sciences, 26: 139-53.

Colman, A. M., Pulford, B. D., and Rose, J. (2008). Collective rationality in interactive decisions: Evidence for Team Thinking. Acta Psychologica, 128: 387-397.

Cummiskey, D. (1996). Kantian Consequentialism. New York: Oxford University Press.

Elster, J. (1989). The Cement of Society. Cambridge: Cambridge University Press.

Feldman, F. (1997). World utilitarianism. In Feldman, F. (1997). Utilitarianism, Hedonism, and Desert. Cambridge: Cambridge University Press: 20-35.

Gold, N. and Sugden, R. (2007). Theories of Team Agency. In Peter, F. and Schmid, H. (eds.) (2007). Rationality and Commitment. Oxford: Oxford University Press: 280312.

Goldman, H. S. (1976). Dated Rightness and Moral Imperfection. The Philosophical Review, 85: 449-87.

Hooker, B. (2000). Ideal Code, Real World. Oxford: Clarendon Press.

Howard, J. V. (1988). Cooperation in the Prisoner's Dilemma. Theory and Decision, 24: 203-13.

Hurley, S. L. (1989). Natural Reasons. New York: Oxford University Press.

Hurley, S. L. (1991). Newcomb's Problem, Prisoners' Dilemma, and Collective Action. Synthese, 86: 173-96.

Hurley, S. L. (1994). A New Take from Nozick on Newcomb's Problem and Prisoners'

\footnotetext{
${ }^{23}$ I am very grateful to the late Susan Hurley, the late Michael Bacharach, and Alex Gregory for very helpful discussion of these issues. I am especially grateful to three anonymous referees and to Stephen Butterfill and Natalie Sebanz, all of whose extremely useful and generous comments helped me greatly improve this paper.
} 
Dilemma. Analysis, 54: 65-72.

Hurley, S. L. (2005). Social Heuristics That Make Us Smarter. Philosophical Psychology, 18: 585-612.

Jackson, F. (1987). Group Morality. In Pettit, P., Sylvan, R., and Norman, J. (eds.) (1987). Metaphysics and Morality. Essays in Honour of J. J. C. Smart. Oxford: Basil Blackwell: 91-110.

Jackson, F. and Pargetter, R. (1986). Oughts, Options, and Actualism. The Philosophical Review, 95: 233-255.

Levi, I. (1997). The Covenant of Reason. Cambridge: Cambridge University Press.

Lewis, D. (1986). Convention. Oxford: Basil Blackwell; originally published 1969.

McClennen, E. F. (1985). Prisoner's Dilemma and Resolute Choice, in Campbell, R. and Sowden, L. (eds) Paradoxes of Rationality and Cooperation. Vancouver: The University of British Columbia Press: 94-104.

McClennen, E. F. (1990). Rationality and Dynamic Choice. Cambridge: Cambridge University Press.

Mulgan, T. (2001). The Demands of Consequentialism. Oxford: Clarendon Press.

Parfit, D. (1987). Reasons and Persons. Reprint with corrections. Oxford: Clarendon Press.

Parfit, D. (2011). On What Matters. Oxford: Oxford University Press, forthcoming.

Regan, D. (1980). Utilitarianism and Co-operation. Oxford: Clarendon Press.

Schelling, T. C. (1980). The Strategy of Conflict. Cambridge, MA: Harvard University Press; originally published 1960.

Sobel, J. H. (1976). Utilitarianism and Past and Future Mistakes. Nô̂s, 10: 195-219.

Sugden, R. (1993). Thinking as a team: Towards an explanation of nonselfish behavior. Social Philosophy and Policy, 10: 69-89.

Sugden, R. (2000). Team Preferences. Economics and Philosophy, 16: 175-204.

Woodard, C. (2003). Group-based reasons for action. Ethical Theory and Moral Practice, 6: 215-229.

Woodard, C. (2008a). A New Argument Against Rule Consequentialism. Ethical Theory and Moral Practice, 11: 247-61.

Woodard, C. (2008b). Reasons, Patterns, and Cooperation. New York: Routledge.

Woodard, C. (2009). What's wrong with possibilism. Analysis, 69: 219-226.

Zimmerman, M. J. (1996). The Concept of Moral Obligation. Cambridge: Cambridge University Press. 